\title{
Computer Monitoring: The Hidden War Of Control
}

Kevin P. Pauli, Mississippi College, USA

Tammy Y. Arthur, Mississippi College, USA

\begin{abstract}
Monitoring has become the battleground for control between labor and management. A model is proposed which examines the dynamics of monitoring on labor through three functions. The first is the use of computer monitoring to reduce the worker to simply another part of the whole machine. The second function is to reduce workers to numbers arranged by their ability to meet mechanistic goals and objectives. The third looks at the ability of monitoring to reduce costs beyond automation through its elimination of supervision and middle-management. Implications are discussed.
\end{abstract}

Keywords: monitoring; control; capitalism

\section{INTRODUCTION}

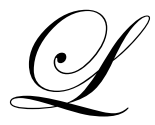

abor today is under assault by the capitalists. In 2007, 66\% of employers surveyed by the American Management Association (AMA) monitored employees' Internet connections (AMA 2007). In 1996, more than 20 million workers in the United States alone were subjected to some form of electronic monitoring through computers (Greengard, 1996). Today, almost $80 \%$ of workers are monitored by their employers (Scott, 2001). Current laws consider the issue to be a private one and provide little protection for the worker.

As computers and computerized automation continue to expand into the workplace, workers will be exposed to greater levels of computer monitoring. Yet, in discussions of computer monitoring and its ethics (Fieser, 1996, Pierce \& Henry, 1996) or impact (George, 1996), management is always assumed to be right in implementing it, without considering why it is implemented or how it effects the workers.

This paper defines a model which identifies the major reasons for monitoring by the organization and the effects of that monitoring on the workers. Classic capitalist and Marxist theory will be used to try and identify the reasons and reactions of those involved within the monitoring process.

\section{CAPITALIST THEORY}

Marx (1887/1978) described a capitalist as the "possessor of money," a "rational miser," and the "owner of the means of production". The capitalist is the provider of capital, the buyer of labor and the producer of goods. The ideal and rational capitalist of Adam Smith (1776/1937) and Emile Durkheim (1893/1984) is a "man" who, through natural selection and access to capital, desires to make a profit.

The capitalist is committed to the maximization of profit. This concentration on profit and minimization of cost leads to improved production efficiency and lower costs. The capitalist, is supposedly constrained by other capitalists, the buyers of goods, the sellers of labor, and the magical balance called "equilibrium." At some price, the sellers of goods will enter the market and at another price, the buyers of goods will leave the market. It is the point at which both exist in unison that is the focus of the magic balance. However, this magic balance also assumes many things that do not exist even today. Among these missing balancers are perfect information and pure competition. The buyer and seller of today are faced with numerous choices and decisions for which perfect information is not available. Marketing schemes and advertising campaigns are developed around the ability to 
influence buying behavior without disclosure of complete information. Open and free competition also requires that the sellers be small, numerous, and independent - a difficult feat in the monopolistic, or at least oligopolistic market structure of today. These same weaknesses are also weaknesses in the area of buying and selling labor.

\section{LABOR}

Labor, as a concept, goes back to the dawn of time; the concept of labor as a class goes back to Marx (1852/1978a p. 608):

In so far as millions of families live under economic conditions of existence that divide their mode of life, their interests, and their culture from those of the other classes and put them in hostile contrast to the latter, they form a class.

Laborers become a class in their division from the capitalist, or owning class. The laborer is the producer and is bought and sold, not on the basis of his/her skills and abilities, but rather on his/her ability to provide labor power to be used and consumed in the production of capital commodities. The laborer is alleged to have free choice to sell his/her labor power at a fair price, but again this infers access to information, freedom of movement, and open market access -- concepts which do not exist in reality. Capitalists compete to hire labor, but set the level of pay in collusion.

To protect the laborer from the excesses of the capitalist, governments have introduced labor laws. However, the government, which should provide protection on behalf of labor, has served mainly to strengthen the hand of the capitalists. James Atelson found five common assumptions in US labor law (cited in Zuboff, 1988):

1. Laws must maintain the continuity of production.

2. Uncontrolled employees will act irresponsibly.

3. Employers are owed respect and deference by their employees.

4. Management may apply unilateral control.

5. Critical decisions about the organization are exclusively the right of Management.

The capitalist enterprise is always seeking to maximize profit and reduce cost. In the first discussion of these concerns, Adam Smith (1776/1937) identified the division of labor as the means to the magic of labor equilibrium. By designing jobs that were more efficient and less difficult to learn, labor could earn more and capitalists could increase profit - a perfect match and much better than the "evil" feudal system. This grand illusion only served to distract the laborer. However, the difficulties of the free market were still there, as the market for labor also lacked perfect information and free competition, as well as unequal power, lack of ownership of the means of production, and excessive supply. So the capitalist determined the role of labor and enforced compliance with a legally reinforced iron fist since, of course, it was "natural" to have the inferiors listen to the superior "men" capitalists and their government.

Without protection and limited in their options, laborers poured their life energy into production, only to have the capitalist capture it as surplus value and profit. Human life became the medium of exchange (C) to transform the capitalist money (M), into simply a larger amount of money (M') (Marx, 1887/1978).

\section{AUTOMATION}

The division of labor was seen as the great provider of production efficiency in the early capitalist economies, but it became a requirement when machines allowed for automation. Marx saw automation as "a moving power that moves itself... so that the workers themselves are cast merely as its conscious linkages" (Marx 1939/1978b p. 279). Yet automation still held the promise of changing the dark and dangerous work of the laborer into the stimulating and prosperous work of the intellectual. Adam Smith (1776, p.272) proposed that the increase in machinery was a benefit to all of society, since if a machine takes fewer men to operate, but still produces the same quantity of product, then the capitalist will use the newly freed laborers and additional machines to further increase production. The fallacy of this growth has been clear since the turn of the century as unemployment, 
underemployment, and poverty have continued to plague society. As the automated machine gained a foothold in the factory, the crisis of "technological unemployment" and obsolete workers became a serious issue for all except the growing corporations (“Obsolete man” 1932).

Peter Drucker (1954) argued that with automation, the worker will have to do fewer repetitive "chores," but would still maintain and control the machine, especially as the semi-skilled machine "handling and feeding" positions are eliminated by the machine itself. Arguing further that the "worker's participation in modern mass production and process production is of the essence, it may well be the critical and controlling factor" (pg. 265). Yet, the automated workers seen by Zuboff (1988) had only repetitive chores - no control, explicit instructions, and constant monitoring. The production process, which will leave all people "free", is an illusion which has haunted us for well over 200 years (Lasch, 1987).

The primary automation of today is done with computers and computer-controlled machines, systems which are so complex and integrated that even the limits of a single machine become hard to distinguish (e.g. "the" Internet, a distributed computer network, without any coordinated structure). Computers and automation in the twentieth century are synonymous, thus to discuss automation in the present context, a brief history of automation and computers is necessary.

\section{Computers}

Most discussions of the history of the computer begin with the pioneering work in the field of mechanical calculation by Pascal, Leibniz, and Babbage. However, the initial impact of these machines was of a more scientific than practical significance. In terms of computers and their impact on the work of people in businesses, the history began with Joseph Jacquard.

In 1804, Jacquard introduced a loom operated with punched cards. The loom was not only a more efficient machine, but it reduced the need for labor required to operate the loom from two skilled workers and one child (i.e., drawboy) - often the son of a loom operator - to only one operator (Freed, 1995). The impact was enormous and unpopular. Ultimately, Napoleon and France, in their role as government, gave Jacquard a patent and small royalty, but claimed the invention as public property and made it available to all weavers (Derry \& Williams 1993).

The concepts originally introduced with Jacquard's loom became, intentionally or unintentionally, part of the punched card census reader developed by Herman Hollerith for the 1890 census (Austrian 1982). Using a system of punched cards and mercury-filled switches, the machines could tally each person's response to the census and tabulate the results mechanically. Again, efficiency was the gain, as the work of the census compilation was reduced from 7 years to less than 2 - fewer workers and faster results. Hollerith, true to the capitalist spirit, founded a company to introduce and lease these wondrous services to the vast and profitable world of business. The business would later, after several iterations, become International Business Machines (IBM) ("International Business Machines", 1932).

During the next 100 years, the computer would move into business as never before imagined. The mercury pool was replaced by the vacuum tube, the vacuum tube replaced by the transistor, the transistor replaced by the integrated circuit, and the integrated circuit replaced by the microchip. Each change, each step increased the complexity and speed of the system and removed the user farther and farther from an understanding of how the system operated.

The 1960's and 1970's saw the rise of distributed computing, terminals linked through a central hub, but operated separately and distinctly. Users were enabled to apply unique system software to diverse problems, in diverse locations, at the same time. It was at this point that consolidated management of distributed computing began. In the older systems, the system managers were those who processed everything and maintained the system, and in the new system, these people now became the system administrators, charged with simply insuring that the system kept working to answer the demands of the various users. 
The personal computer (PC) became a dominant force in the 1970's and 1980's. Users no longer were locked to a single mainframe. Processing could be done remotely and independently and on computers now being found on users' desks. Computers also became a significant portion of the production automation processes. Information on production and process was generated, along with the instructions of what needed to be done. The computer had become the electronic "tattletale" (Zuboff, 1988).

The 1990's to the present have seen the rise of the Internet and computer networks. Computing is once again controlled through centralized servers. Users, while performing distributed processing, are also storing information on networked drives and communicating by e-mail. The Internet has provided the ability to share a vast range of information with assumed anonymity. System administrators once more become the hub support and information gatekeepers.

\section{MONITORING}

The simple days of the time-clock are over. Today, technology produces so much information about workers that it is no longer a question of what you do, but what the systems says you do. Today the systems that monitor workers can be either passive or active monitoring systems.

The first type of system, passive, provides data on the worker as a by-product of the production process. A manager within the Zuboff (1988, p.316) study said, "I can find out everything you did except for what went on in your head," in his description of the information he could generate.

These passive systems provide information, created during other processes, that gives a clear description of the activities done by the worker. These are systems, such as automated processing systems, which record the actions of workers and their impact on production flow; data recorders, like those used in the "black box" of aircraft, which can pinpoint exactly what happened in a given accident; production control systems, which record line flow and interruptions and can be used to identify actions which help or hinder the peak efficiency of a process (Zuboff, 1988).

The second type of monitoring systems is the active tracking systems. These are the systems whose purpose is to actively monitor the actions and activities of the workers. Examples of these types of systems include keystroke counting software, which tracks the keystrokes per-minute of computer operators; computer log-in tracking, which provides a time coded log of all activities performed from a specific computer terminal or log-in account; and web access monitoring software, which tracks the specific websites visited by a certain user and generates a report of the site, time and length of time visited. Each of these systems provides active, intentional monitoring, generally tied in with a reporting and recordkeeping process.

The employer of today has the ability and legal right to read e-mail, review files stored on a company computer, examine computer usage, and track individual employee computer activities. The idea of anonymous actions is an illusion. Every action between a network and the computers connected to it can be tracked. Every action by an individual worker on a computer can be tracked, analyzed and used against the employee. The protections and freedoms guaranteed by the U.S. Constitution and Bill of Rights are there to protect the individual from the Government and do not generally apply to the normal employee/employer relationship.

Monitoring is also a hierarchical issue. Who is monitored? In organizations in which computer monitoring is done, how far up the chain-of-command does the monitoring go? The inclusion of workers at the production level of the organization is almost a given; however, the monitoring is usually stopped before it goes too far up the line. Owners and managers are not workers and can be trusted, at least they think so (Zuboff, 1988). So where do the network administrators fit?

Network administrators are high in expert power, but they are generally in support roles to the overall management of the organization. These individuals are placed as the gatekeepers between the workers and the overseers. They are the keepers of the key. Their actions provide the ability of the manager to become overseer. Their lack of actions allow the worker to be the subject of the oversight. 
What of privacy? What of duty to inform? These are concepts which do not enter the current monitoring situation. The work of the worker is open to the observation and dissection of the manager. There is no requirement even to inform the worker that they are being monitored. Information can be collected, stored and used against the employee without the employee ever knowing. The systems currently employed to monitor through a network do not even indicate that the monitoring is occurring. E-mail can be saved, reviewed and shared without the knowledge or consent of the e-mail writer. The technology of computers has become the all-seeing eye of "Big Brother."

Monitoring in the factory and office of today is used to watch, measure, track and analyze the worker. Nothing is private and nothing is unseen. The worker becomes a mouse in a glass cage.

\section{PURPOSE OF MONITORING AND AUTOMATION}

The development of monitoring within organizations maintains the capitalist domination over labor in three ways: 1) through the maintenance of a powerless workforce, 2) through the maintenance of a controllable workforce, and 3) through the maintenance of an inexpensive workforce (Pfeffer, 1982). Each of these will be discussed. While each is a separate and identifiable aspect of the monitoring relationship, they all operate together to achieve aims that result in less than human relations between the capitalist and the labor provider.

In graphic terms, the monitoring provides oversight without contact between the capital owner (capitalist) and the provider of the labor power (laborer). As shown in Figure 1, the monitoring process provides the capitalist with the ability to control, the power to manage, and the knowledge to minimize cost of the labor, while simultaneously providing the consequences of these activities to the workers.

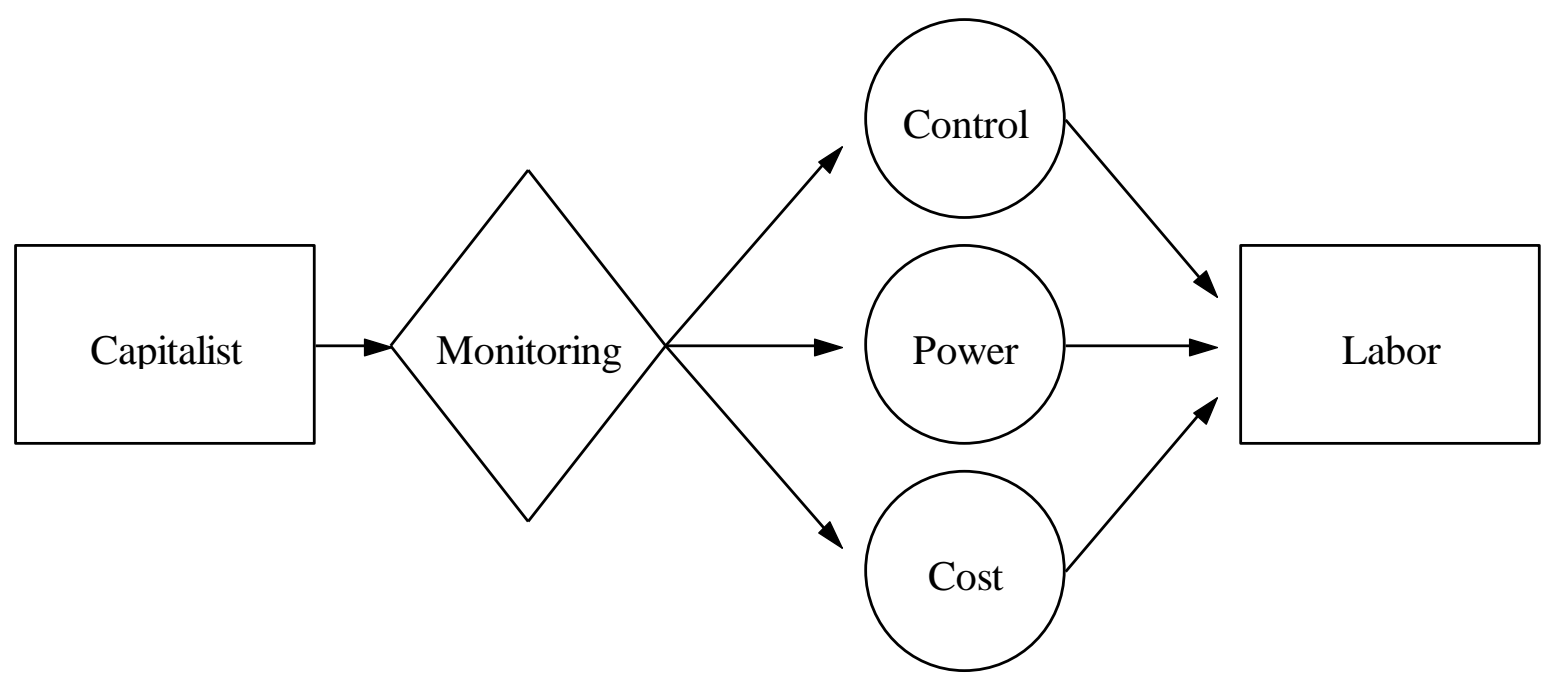

Figure 1: Monitoring Process

\section{Power}

Through the use of computer monitoring of activity and performance, the worker is reduced to part of the whole machine. The first loss to the worker was de-skilling, through the introduction of automation, which reduced the skills needed by the worker and allowed for increased production with less skill, rendering the worker an inexpensive bulk commodity. The second loss to the worker was monitoring, which was more subtle and caused the worker to doubt his/her own self worth, trustworthiness, and image. 
No longer can a worker even confront the facts presented about him/her. The data is computer processgenerated and seemingly unquestionable, regardless of the actual accuracy or the basis upon which it was collected.

Workers are tracked, scanned, rated, graded, scored, and ranked with machine efficiency. The ability to present the "soft," non-technical, reasons for failure is removed. Managers complain that they must try to read output and guess what is going on "inside workers heads," only to end up evaluating performance on issues, such as who talks the most or dresses the best (Zuboff, 1988). The worker is forced to conform to the demands of the machine and to work within the new operating parameters. The worker becomes just another piece of capital, as so long ago argued by Marx - not the free and enlightened individual pictured by Drucker (1954).

Monitoring also divides the functions of each worker from each other and the process as a whole. Each laborer now interacts with an automated portion of the whole, alone, watched and tracked by the monitoring system. Even the manager is no longer required to interact with the line workers face-to-face, but monitors their production and performance as reported by the monitoring system (Zuboff, 1988). Workers are divided by the division of labor and the automated process until only the monitoring system can even see what they do "on the line."

Active monitoring also provides for insight into activities a worker participates in outside the production process. Discussions and communications become subject to examination. Conversations are no longer private or passing. Those fomenting dissension can be systematically identified and removed. "We are used to face-to-face interactions where words disappear...I assumed keyboard communication was like a letter or a phone call, but now I understand that it doesn't disappear...The myth is that electronic communication is invisible" (Zuboff, 1988, p. 381).

All manner of oppressive control can be applied based upon information gathered through the careful watching of the worker. The worker becomes fearful, timid, and ultimately powerless to challenge the power of the new overlord, the capitalist. "Big Brother" is not the faceless government, but the heartless capitalist.

The elimination of privacy and autonomy are not the only power destroying weapons within the arsenal of automation and technology. Through the limiting of training opportunities for those charged with the operation of the technology, users are left without an understanding of the very systems they operate, allowing management to control the process and those interacting with the technology and maintain their expert knowledge power.

System settings and controls become the domain of the technocrats and overseers. Control of the key program variables and settings allows those in charge of the system to set the limits on what must be done. In the Zuboff study the computer system used to schedule jobs was programmed to exceed eight hours of work a day:

The idea was to drive the craftsperson as hard as possible ... This way we end up with an eight-and-one-half-hour load; but if we push them, they will do the work and probably do many of the jobs in less time than we assigned (Zuboff 1988, p.330).

Labor is reduced to a "cog" of flesh and blood in the automated factory of today. Processes are designed with an almost mindless obsession with the minimization of human involvement and knowledge. Any process that can be coded into a computer and performed will be. The laborer loses his/her identity within the black gut of the automated machine; each is alike, each is interchangeable, and each is replaceable. Without voice and without power, the labor becomes simply another tool of the capitalist - the bleeding heart of a soulless machine - for as Brown (1996) said, "if technology exists, it must be used."

\section{Control}

Brown (1996) argued that the very existence of technology insures its usage as a means of control. Technological automation sets the standard and monitoring provides the grade. Workers are rated by their ability to meet goals and objectives, optimized not by the abilities or even tolerance of the human body and mind, but rather by the productive and efficient capacity of the machine. 
Workers fear their tools and machines because they no longer understand how they work. Unlike the idealistic vision of a "highly skilled and highly trained" workforce (Drucker, 1954, p. 21), there is, instead, the minimally trained laborers of modern automation.

The knowledge of the system becomes the power of the capitalist. To insure the ultimate control of the system, the knowledge is parceled out among numerous parties to insure only one group controls the whole system. The manager has access to reports, the worker performs the process, the engineer understands the process, the system administrator oversees the transfer to the manager, and the capitalist controls each. No one will share their information for fear of the loss of their functional existence; each hordes their knowledge to insure their continued existence within the system. The capitalist controls all by having the only complete knowledge of the system.

The monitoring is made to be insidious. Within the monitoring system, the process is made invisible. Those being monitored know, but they do not know the extent. Hidden is the complete knowledge of what is seen and heard. Workers must operate under assumptions of the system without understanding any of its true nature. The employment relationship is then structured so that the power of capitalists over laborers is largely hidden and control over the workers and managers is achieved.

This continuous functioning of power, through its perceived potential continuous application, is the basis of panoptic control, based on Jeremy Bentham's "Panopticon" (Zuboff, 1988, Foucault, 1977, Brown, 1996). The worker never knows what is being seen and heard. All communication and action must be performed within the accepted rules or someone will see, someone will know. The watcher watches and is never seen, the watched is watched, but never sees.

Foucault's description of a prison, based on the Panopticon, could easily be used to discuss the use of monitoring in the automated workplace of today. Foucault proposed that the overseer "arrange things" such that "the surveillance is permanent in its effects, even if it is discontinuous in its actions". The unseen control is so effective that it should "tend to render its actual exercise unnecessary" (Foucault 1977, p.201).

Secrets become impossible. The panoptic system of control works because no one knows if they are being watched. Those being monitored must assume they are always subject to the monitoring, because the monitoring could be on all the time. This secrecy sometimes leads to unintended behaviors. It can lead to the challenge of laborers to find the limits of the oversight to try and thwart "omniscience" (Zuboff, 1988, p.352). But the attempts of labor to change the system are thwarted by the system and the self-preservation desire of those within the system. Labor is divided and conquered.

The elimination of labor power, however, does not stop at the line. In the automated factory of today, the hierarchical structure is inefficient and unnecessary. Automated mass production, automated monitoring, and expert systems encourage the use of flat structures and have challenged managers' right to exist as well (Sullivan, 1987). In the Zuboff study, managers who supported their increased monitoring and oversight of the line workers became concerned about those trying to look over their shoulders:

They [senior management] want to have access to real-time data from the mills. But as plant manager, I do not want to be second guessed. I don't want them breathing down my neck or wasting their time on the nitty-gritty from the shop floor. Right now, I have some flexibility in terms of deciding what data they see, when they see it, and how it is presented. If I lose control over that, it is an important piece of my job over which I will have lost control. (Zuboff 1988, p. 339)

Monitoring systems which track the minute-by-minute production of one employee can be aggregated to a collection of employees, a line, a department, a division, a branch, or even an entire sub-company. Monitoring in real time means the managers at every level are subject to the same tracking as those below. Monitoring of managers can also lead to attempts to beat the system and remain free, using collusion and expert power to limit the hierarchical spread of information (Zuboff, 1988). The social expectations of the worker are there, regardless of the level of hierarchy examined. The capitalist has hidden the process to insure the control. All workers live under the shadow of the all-knowing eye. 


\section{Cost}

The capitalist orientation is simple - maximize profit. The introduction of monitoring must provide a reduced cost in order for the capitalist to use it. First, the technology reduces the level of craftsmanship, or skill, necessary to perform a given task. Second, the technology increases the efficiency of the production process so that more products can be produced with less labor. The use of monitoring, however, adds a third area of cost reduction, the elimination of supervision and middle-management.

The division of labor provided an initial push toward the deskilling of workers, and therefore, the lowering of the cost of labor. The introduction of automated processes has pushed the deskilling to even greater levels. Those hired need to understand only a small area of their function and must follow the guidance of those with knowledge power (e.g. managers). Monitoring provides immediate feedback to insure that a lack of skills does not compromise the profit of the capitalist. Behaviors that negatively impact profit can be identified and those guilty held up for public humiliation and private subjugation. Labor becomes de-skilled and, as such, less expensive to buy and easier to replace.

Automation and monitoring also reduce the number of workers needed to perform a task. Systems are designed to handle large portions of the task, leaving the simple aspects to the operator. Monitoring provides realtime and archived records of what is happening and what has happened, thus allowing those in charge, an inexpensive way to re-create and re-examine any aspect of the process done by the worker.

The final cost savings from the automation and monitoring process are reduced supervision expenses. Monitoring and automation have eliminated the special knowledge of the craftsman and crew chief (Zuboff 1988). Monitoring provides direct information on performance, which allows for the elimination of the messiness of human contact. Supervision of a very large number of workers can be monitored by a single supervisor or, even better, an exception tracking system, allowing a flat organization and fewer levels of management control.

While the benefits may be great, the true capitalist would prefer that the monitoring occur as part of a larger passive tracking system in order that additional costs not be incurred. However, the capitalist would base the decision to implement additional monitoring not on a malicious or capricious whim, but simply on the net gain in profit resulting from the change. Simply put: Would the introduction of any monitoring technology improve the profit of the organization?

\section{Other Considerations}

What is truly fascinating here is that the capitalist would not implement a surveillance technology simply to keep labor "down." The technology must provide a cost benefit. Implementing monitoring to maintain a division of labor must be profitable. To do this, the system must do one of two things - either increase the end product value (e.g. quality, consistency, quantity) or decrease the cost of supervision.

The capitalist is unconcerned, in general, with the ethics of the monitoring process. Only if the ethics involved effect the demand for the product, the labor cost, and/or the overall profit of the organization would the ethics become a concern. The modern distribution of the market for products has undercut most of the muscle behind the original assumptions of informed consumers, but if a corporate action was so heinous as to actually impact the profitability or survivability of an organization, it should change its behavior.

An organization that is in violation of socially established rules of conduct may find it is in violation of law as well. To the rational consequential capitalist, a violation of law would be weighed against the same scale as any other decision made - does the cost outweigh the benefit. If the benefits received from violation of a law are sufficient to offset all the costs, then an organization will violate the law. In the case of monitoring, there are currently very few laws or regulations, so the potential cost to an organization is minimal.

Labor cost, on the other hand, is highly susceptible to the effects of ethics. An organization which does not follow good business ethics may find itself having to pay more costs in turnover or worker dissatisfaction. 
Concepts, such as "goldbricking" (Roy, 1952), loafing, and "soldering" (Taylor, 1939), have been used to describe this process of worker retaliation and reaction; but will this cause an employer to change? Only if the total costs associated with these actions becomes higher than the total benefits. The capitalist does not do anything simply to be capricious; the hook is always the money. If an action is taken, it must lead to increased profits.

So in a capitalist's world, the decision to monitor employees would be done after careful consideration of the costs and benefits associated with the action. Simply put, automation and monitoring allows the capitalist to pay less for the labor needed in the operation of their systems. The ultimate, cost minimization/profit maximization objective of the capitalist is met and the monitoring is justified.

\section{CONCLUSION}

Technology is driving production to levels of efficiency never before imagined. Even simple tasks, like writing, have been converted into high technology means of production. Do we, as writers, even understand a fraction of what the technology on our desk does? Are we, as workers, aware of what the computer tells those we work for about us and what we do? I think it naive to believe that the system will be swayed by words of condemnation as there is no profit in it. There is, however, a need to reconsider the human elements of the production process, reduced to fleshy cogs in the high technology production of today.

Foucault (1977) described the Panopticon as able to induce "a state of conscious and permanent visibility that assures the automatic functioning of power" (page 201). The prisoners of the Panopticon had one advantage over the worker of today; however, they knew that they would one day be free. The computer network of today is the new Panopticon, but without the steel, wire, glass, and mirrors required in the original prison.

Through automation, the worker can be given the opportunity to think about larger issues of production, but only if allowed to. Management must realize that the mind numbing boredom involved in staring at a screen of numbers, waiting for something to happen, can do more than give the workers a stiff neck (Zuboff, 1988).

Against the loss of power, control and income, workers will respond with less effort and eventually organized action. Workers subject to the oppression of management through monitoring will find ways to "cheat" the system. Holes in the all-seeing eye will be utilized to reduce effort. Managers, workers, and system administrators will attempt to collude to insure protection and freedom from monitoring (Zuboff, 1988). Workers will fight a million tiny battles, always looking to balance the dissonance between expectations of performance and levels of compensation.

Collective action in and across all levels of the organization, in formal and informal forms, will attempt to change the structure. Manager, supervisor, craftsman, and laborer are united in a battle of survival, and so the battle to change the system has begun. Labor and capital are battling for control. Monitoring has become the seed of its own destruction.

\section{AUTHOR INFORMATION}

Kevin P. Pauli is an Assistant Professor of Management Information Systems and Management at Mississippi College. He earned his Ph.D. and MBA at the University of Nebraska - Lincoln. He has worked for many years on issues relating to computer ethics, learning, and use. Current research interests include ethical decision making, privacy, computer learning and usage, and computer monitoring. Professor Pauli's articles have appeared in Business and Society, the Journal of Educational Computing Research, Business Journal for Entrepreneurship, and Review of Business Information Systems Journal.

Tammy Y. Arthur is an Assistant Professor of Management Information Systems and Entrepreneurship at Mississippi College. She holds an MBA from the University of Southern Mississippi and a Ph.D. from Mississippi State University. She spent many years in IT Management at Bellsouth. Professor Arthur's current research interests are in entrepreneurship, ethics, contract workers, and learning. Her work has appeared in the Review of Business Information Systems Journal and Business Journal for Entrepreneurship. 


\section{REFERENCES}

1. Brown, W. (1996). Technology, Workplace Privacy and Personhood. Journal of Business Ethics, 15. 12371248.

2. Derry, T.K. \& Williams, T. I. (1993) A short history of technology: from the earliest times to A.D. 1900

New York: Dover Publications.

3. $\quad$ Drucker, P. (1954). The Practice of Management. New York: Harper \& Row.

4. Durkheim, E. (1984). The Division of Labor in Society. (W.D.Hall, trans.).New York: The Free Press. (Original work published 1893)

5. Fieser, J. (1996). Do Businesses have Moral Obligations Beyond What the Law Requires? Journal of Business Ethics, 15, 457-468.

6. Foucault, M. (1977). Discipline and Punish: The Birth of the Prison. (A. Sheridan, trans.) New York: Pantheon Books.

7. Freed, L. (1995). The History of Computers. Emeryville, CA:Ziff-Davis Press.

8. George, J. F. (1996). Computer Based Monitoring: Common Perceptions and Empirical Results. MIS Quarterly, 459-480.

9. $\quad$ Greengard, S. (1996). Privacy: Entitlement or Illusion. Personnel Journal, May 74-88.

10. Lasch, C. (1987). Technology and Its Critics: The Degradation of the Practical Arts. In S.E. Goldberg \& C.R. Strain (eds.), Technological Change and the Transformation of America. Carbondale: Southern Illinois University.

11. Marx, K. (1978). Capital, Volume One. In R. C. Tucker (ed.), The Marx-Engels Reader. (2nd ed.). New York: W.W. Norton \& Company. (Original work published 1887)

12. Marx, K. (1978a). The Eighteenth Brumaire of Louis Bonaparte. In R. C. Tucker (ed.), The Marx-Engels Reader. (2nd ed.). New York: W.W. Norton \& Company. (Original work published 1852)

13. Marx, K. (1978b). The Grundrisse. In R. C. Tucker (ed.), The Marx-Engels Reader. (2nd ed.). New York: W.W. Norton \& Company. (Original work published 1939)

14. Pfeffer, J. (1982). Organizations and Organization Theory. Marshfield MA: Pitman Publishing, Inc.

15. Pierce, M. A. \& Henry, J. W. (1996). Computer Ethics: The Role of Personal, Informal, and Formal Codes. Journal of Business Ethics, 15. 425-437.

16. Roy, D. (1952). Quota Restriction and Goldbricking in a Machine Shop. American Journal of Sociology, 427-442.

17. Scott, A (2001) No Privacy in the Workplace. Internal Auditor, Jun2001, 58 (3), 15-18.

18. Smith, A. (1937). An Inquiry into the Nature and Causes of the Wealth of Nations. New York: The Modern Library. (Original work published 1776).

19. Sullivan, B. (1987). The Challenge of Economic Transformation: Forerunner of Democracy. In S.E. Goldberg \& C.R. Strain (eds.), Technological Change and the Transformation of America. Carbondale: Southern Illinois University.

20. Taylor, F. (1939). The Principles of Scientific Management. New York: Harper \& Row.

21. Zuboff, S. (1988). In the Age of the Smart Machine: The Future of Work and Power. New York: Basic Books, Inc.

22. (1932). Obsolete Man. Fortune, December. 25-34, 91-94.

23. (1932) International Business Machines. Fortune. January 1932. pp. 34-40.

24. Derry, T. K. \& Williams, T. I. (1982) A Short History of Technology. London: Oxford University Press.

25. Austrian, G. (1982) Herman Hollerith, forgotten giant of information processing. New York: Columbia University Press.

26. 2007 Electronic Monitoring \& Surveillance Survey. American Management Association and The ePolicy Institute. 2007. (http://press.amanet.org/press-releases/177/2007-electronic-monitoring-surveillancesurvey/) 